\title{
Erratum to: Older age at the completion of linear growth is associated with an increased risk of adult glioma
}

\author{
Rebecca B. Little ${ }^{1}$ L. Burt Nabors ${ }^{2} \cdot$ Jeffrey J. Olson $^{3} \cdot$ Zachary J. Thompson $^{4}$ • \\ Carrie M. Rozmeski ${ }^{4}$ - Renato V. LaRocca ${ }^{5}$ - Peter A. Forsyth ${ }^{6} \cdot$ Reid C. Thompson ${ }^{7}$. \\ Robert A. Oster ${ }^{8} \cdot$ Sajeel A. Chowdhary ${ }^{9} \cdot$ Kathleen M. Egan ${ }^{4}$
}

Published online: 28 April 2017

(C) Springer International Publishing Switzerland 2017

\section{Erratum to: Cancer Causes Control DOI 10.1007/s10552-017-0871-5}

Unfortunately, Table 4 was wrongly published in the original publication of the article. The correct version of Table 4 is given below:

The original article was corrected.

The online version of the original article can be found under doi:10. 1007/s10552-017-0871-5.

Kathleen M. Egan

Kathleen.egan@moffitt.org

1 Department of Nutrition Sciences, University of Alabama at Birmingham, Webb 449, 1675 University Blvd., Birmingham, AL 35294, USA

2 Neuro-oncology Program, University of Alabama at Birmingham, FOT 1020, 510 20th St. South, Birmingham, AL 35294, USA

3 Department of Neurosurgery, Emory University School of Medicine, 1365-B Clifton Rd., NE, Ste. 2200, Atlanta, GA 30322, USA

4 Division of Population Sciences, H. Lee Moffitt Cancer Center \& Research Institute, 12902 Magnolia Drive, Tampa, FL 33612, USA
Department of Hematology-Oncology, Norton Cancer Institute, 676 So Floyd St., Louisville, KY 40202, USA

6 Department of Neuro-oncology, H. Lee Moffitt Cancer Center \& Research Institute, 12902 Magnolia Drive, Tampa, FL 33612, USA

7 Department of Neurological Surgery, Vanderbilt University Medical Center, 691 Preston Building, Nashville, TN 37232, USA

8 Department of Medicine, Division of Preventive Medicine, University of Alabama at Birmingham, MT 642, 1717 11th Ave. South, Birmingham, AL 35205, USA

9 Neuro-Oncology Program, Lynn Cancer Institute, 701 NW 13th Street, Boca Raton, FL 33486, USA 


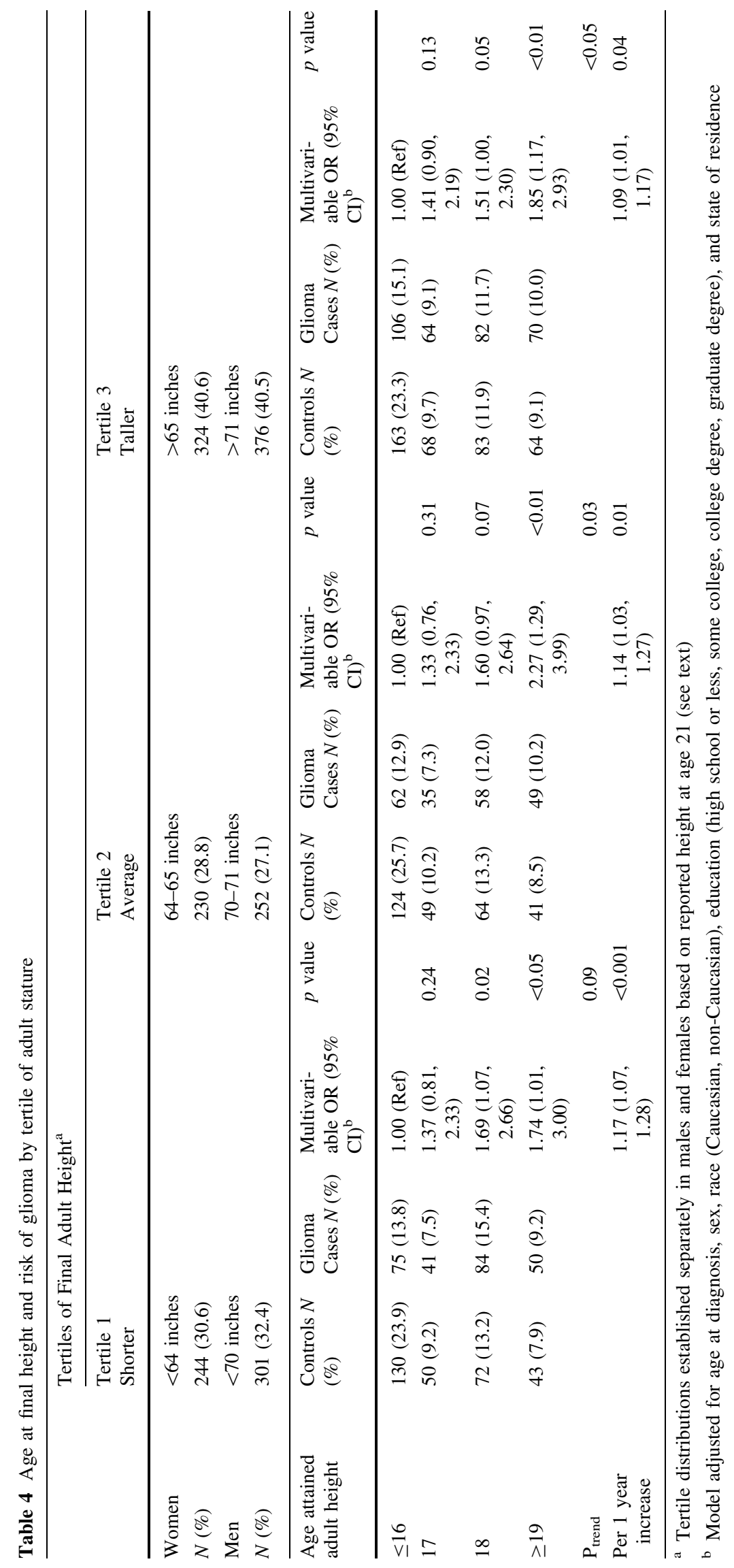

